\title{
The Use of Insulin Pump Therapy in the Pediatric Age Group
}

\section{S. Shalitin M. Phillip}

Jesse Z. and Sara Lea Shafer Institute for Endocrinology and Diabetes, National Center of Childhood Diabetes, Schneider Children's Medical Center of Israel, Petah Tikva, and Sackler Faculty of Medicine, Tel Aviv University, Tel Aviv, Israel

\section{Key Words}

Continuous subcutaneous insulin infusion • Diabetic children/adolescents, life quality $\cdot$ Insulin pump diabetes therapy

\begin{abstract}
Diabetic children and their caregivers face the never-ceasing challenge of maintaining blood glucose levels as close as possible to the normal range so as to prevent or delay longterm micro- and macrovascular complications, to minimize the risk of severe hypoglycemic episodes, and to improve quality of life. Continuous subcutaneous insulin infusion (CSII) therapy represents a treatment option that can aid in achieving these goals. Granted that insulin secretor responses to physiological stimuli are complex and difficult to duplicate, CSII is the most physiological method of insulin delivery currently available, simulating the pattern of insulin secretion with a continuous adjustable 'basal' delivery and superimposed mealtime 'boluses'. CSIl offers greater flexibility and more precise insulin delivery than do multiple daily injections, and thus can reduce the frequency of severe hypoglycemia. However, when CSII was compared to multiple daily injections in randomized crossover or controlled trials in children or adolescents, generally there was no significant difference in $\mathrm{HbA}_{1 c}$. This review briefly summarizes the current state of knowledge regarding the use of CSII in pediatric and adolescent patients with type 1 diabetes mellitus.
\end{abstract}

Copyright $\odot 2008$ S. Karger AG, Basel

\section{KARGER}

Fax +4161306 1234 E-Mail karger@karger.ch www.karger.com
(C) 2008 S. Karger AG, Basel

0301-0163/08/0701-0014\$24.50/0

Accessible online at:

www.karger.com/hre

\section{Introduction}

The goals of intensive management of diabetes have been clearly established by the Diabetes Control and Complications Trial (DCCT) [1]. The two main goals in the management of diabetes are: (1) the avoidance of sustained hyperglycemia to prevent the well-documented long-term micro- and macrovascular complications and (2) the avoidance of recurrent episodes of hypoglycemia, which, especially in the younger years, may adversely affect cognitive function as well as cause emotional morbidity for both child and parents. The never-ceasing challenge faced by diabetics and their caregivers has through the years inspired continuing efforts to find ways and means for achieving better control of blood glucose levels. These include the development of insulin pumps, attempting to mimic the complex mechanism of insulin secretion. The first such pumps, available since the late 1970s [2], proved to be problematic and initial enthusiasm soon waned. With the development of smaller, more efficient and user-friendly pumps, continuous subcutaneous insulin infusion (CSII) is rapidly gaining in popularity and in its present form would appear to be the most physiological method of insulin delivery available.

The following is a brief summary of the current state of knowledge regarding CSII, including its advantages and disadvantages, as used in pediatric patients with type

Institute for Endocrinology and Diabetes, National Center for Childhood Diabetes

Schneider Children's Medical Center of Israel, 14 Kaplan Street

Petah Tikva 49202 (Israel)

Tel. +972 3925 3731, Fax +972 39253 836, E-Mail Mosheph@post.tau.ac.il 


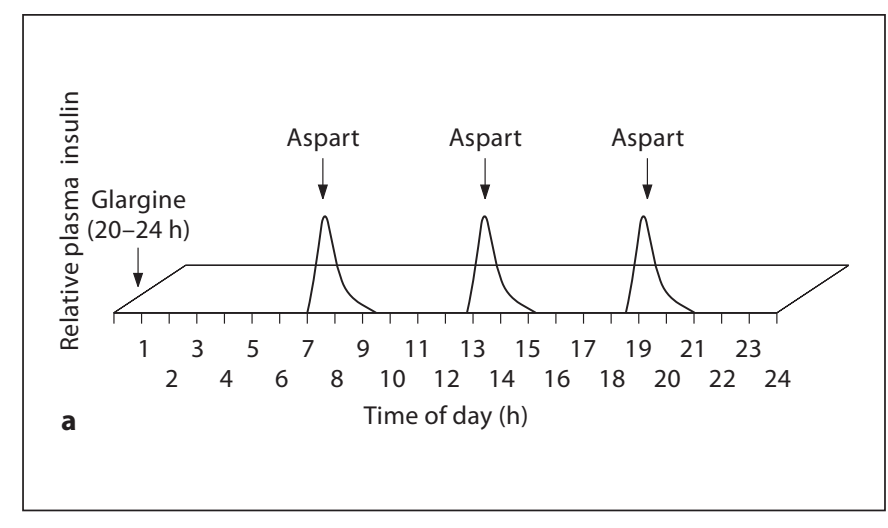

Fig. 1. a MDI of short- and long-acting insulin analogs. MDI allow flexibility of insulin administration (aspart) with meals and a relatively constant level of insulin for basal needs without meals (glargine). However, it does not resolve the necessary changes of insulin dosage with the 'dawn' and 'dusk' phenomena and physical activity. b Insulin pump therapy (CSII). The basal rate supplies

1 diabetes mellitus (T1DM). Most of the data were discussed in the pediatric consensus document that has been published recently [3].

\section{Data Sources}

All articles found in MEDLINE from 1996 to April 2007 that contained the words 'CSII' or 'insulin pump therapy' in children and/or adolescents were included. There were 159 articles listed, including 39 review articles and one consensus statement.

\section{The Basics of CSII}

The pump consists of a device holding a syringe filled with insulin that is delivered by a controlled mechanism pushing the plunger of the syringe down to infuse insulin into the subject via an infusion set inserted into the subcutaneous tissue. It is an open-loop system able to simulate the pattern of insulin secretion with a continuous 24-hour 'basal' delivery of insulin upon which are superimposed mealtime 'boluses'. The basal rate is set to the minimum insulin needed to suppress gluconeogenesis and ketogenesis while keeping blood glucose levels within the normal range without inducing hypoglycemia. The mealtime boluses are calculated with the use of an algorithm and depend on the caloric and nutritive composition of the meal (an option that is not used by all), the

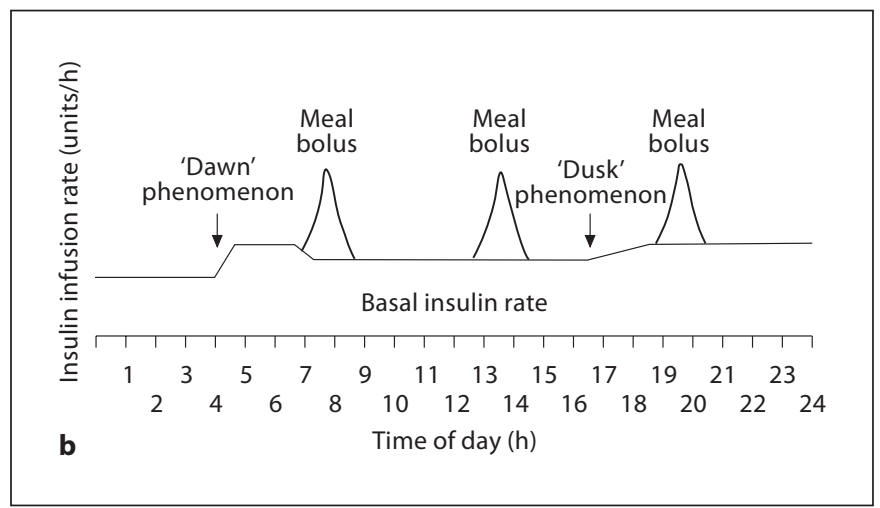

a continuous flow of insulin. The basal rate is increased in the early morning and the afternoon hours when the 'dawn' and 'dusk' phenomena occur. The basal rate can be adjusted to physical activity and even be temporarily stopped. The insulin pump allows flexibility.

capillary glucose concentration before the meal and the anticipated level of physical activity after the meal. The basal and bolus functions of the pump permit separate determination and adjustment of both these insulin requirements as well as flexibility in timing, amounts of nutritional intake and physical activity, allowing for wide variations in lifestyle (fig. 1).

Notable features available in different pumps include: small incremental changes ( 0.025 or 0.05 unit) in basal rates, important when the total daily insulin dose is low (infants and toddlers); automatic calculation of correction boluses based on insulin-to-carbohydrate ratios and insulin sensitivity factors; direct communication with a blood glucose meter, which can assist with bolus dose calculation; alarm features that can remind a child if a meal bolus is missed, and a pump memory able to review insulin boluses, carbohydrate intake used in bolus calculations and blood glucose levels, which can be most useful in the counseling of patients regarding their diabetes management.

\section{Patient Selection}

According to the consensus statement on the use of CSII in the young ages [3], and according to our experience, all pediatric patients with T1DM are potential candidates for the insulin pump, without any age limit. Thus CSII can be safely initiated at diagnosis [4] or anytime thereafter [5]; however prior experience with the use of 
insulin syringes and pens might be of importance in case of pump malfunction and, therefore, we usually educate our patients on their use first before switching to CSII. CSII should be strongly considered (1) for children with recurrent severe hypoglycemia $[6,7]$, unacceptable fluctuations in blood glucose levels regardless of $\mathrm{HbA}_{1 \mathrm{c}}[8]$, suboptimal diabetes control [6], a tendency to develop ketosis, microvascular complications and/or risk factors for macrovascular complications [9] and with good metabolic control but an insulin regimen that unacceptably compromises lifestyle, (2) for competitive athletes, (3) for children with needle phobia, and (4) for young children, especially infants $[5,10-13]$.

\section{Current Experience with CSII Therapy in Children and Adolescents}

Pump therapy should be initiated only after a decision has been made jointly by the child, parent(s) and diabetes team. The consensus report [3] further advises that a pediatric multidisciplinary diabetes team experienced in insulin pump therapy is required to initiate and maintain children successfully on CSII, with frequent contact between the family/child and diabetes team after pump initiation.

Knowledge of pump functions as well as management skills, including proper infusion set insertion, are essential. Weinzimer et al. [10] have found that in young children CSII initiation must include an assessment of caregivers to ensure proper supervision, including responsibility for pump management and blood glucose monitoring.

CSII may be discontinued temporarily or permanently in children or adolescents wishing to return to injection therapy, or when there are conditions putting the child at risk, e.g., recurrent diabetic ketoacidosis (DKA) due to pump mismanagement, ineffective pump management or intentional insulin overdosing to cause hypoglycemia [3].

\section{Type of Insulin Used in CSII}

Many children show rapid fluctuations of their blood glucose levels, a situation demanding rapid adjustment of the insulin dose. Used in CSII, rapid-acting insulin analogs were found to result in a modest but significant reduction in $\mathrm{HbA}_{1 \mathrm{c}}$ as compared with soluble (regular) insulin [14]. Rapid-acting insulin analogs also allow insulin to be delivered during or after the meal, and more frequent bolus doses can be given to correct abnormal blood glucose levels. Although no controlled studies in children are available, the consensus report [3] recommends the use of rapid-acting insulin analogs for CSII [3]. However, in our experience, 'ketone-prone' patients or patients with a tendency to catheter occlusion during the night may benefit from the addition of basal insulin such as insulin glargine injection to decrease the risk of DKA. We have a few patients on this mode of therapy with good compliance and with significant reduction in DKA episodes.

\section{Calculation of Total Daily Insulin Requirements}

The basis for calculating the insulin requirement at the time of pump treatment initiation depends upon the insulin requirement while on multiple daily injections (MDI) and the level of glycemic control. In children with good glycemic control and a low frequency of hypoglycemia, the total dose may need to be reduced by $10-20 \%[11$, $15]$, and with frequent hypoglycemia, the dose should be reduced by $20 \%$. The basal rate is set to the minimum insulin needed to suppress gluconeogenesis and ketogenesis while keeping blood glucose levels within the normal range without inducing hypoglycemia. Typically $30-50 \%$ of the total daily dose is required for basal needs [16] and this is programmed in hourly intervals according to the circadian variation of the patient's insulin sensitivity, which is age dependent [17]. In adolescents, decreased insulin sensitivity is seen particularly in the early morning (dawn phenomenon) and to a lesser extent in the late afternoon (dusk phenomenon). This leads to a typical twowaved basal rate profile. The PedPump Study Group [18] noted that younger children often need more basal insulin between 21.00 and $24.00 \mathrm{~h}$.

Carbohydrate counting is a prerequisite for successful basal-bolus therapy. The premeal boluses are dependent on meal carbohydrate intake, circadian variation of insulin sensitivity, current blood glucose levels and planned activity. Various algorithms exist that assist in calculating insulin-to-carbohydrate ratios. In the Pedpump Study Group report [18], more than seven daily boluses were associated with significantly better $\mathrm{HbA}_{1 c}$ values [18]. In very young children or fussy eaters, some parents prefer to administer the bolus after the meal [19] in order to adjust it to the actual food intake. However, missed boluses are associated with poor glycemic control [20].

The quantity of the corrective insulin bolus depends upon insulin sensitivity and is calculated as the difference between the current blood glucose level and the target level. Some pump models offer calculation tools for this purpose, others require manual formula calculation 
[21]. Infants and toddlers typically have greater insulin sensitivity and, therefore, require less insulin to correct hyperglycemia. Moreover, 'insulin on board' from a previous insulin bolus should be taken into account in determining the subsequent bolus dose to prevent 'stacking' of corrective insulin boluses and consequent hypoglycemia. Newer insulin pumps can calculate the insulin on board' from the previous insulin bolus.

\section{Advantages of CSII}

\section{Glycemic Control}

With CSII, insulin administration is more precise and better matched to food intake and there is less variability of insulin absorption. A number of trials demonstrated a decrease in glucose excursion with CSII with continuous monitoring by glucose sensors $[8,22-26]$. The long-term target, however, remains achievement of a near-normal $\mathrm{HbA}_{1 \mathrm{c}}$, which expresses the control attained over a period of months and serves as a surrogate marker for the degree of risk of late complications. Recently, there has been an increased awareness of the impact of glucose variability on overall blood glucose control and the risk for diabetesrelated complications, which may be increased in those with greater glucose excursions.

Numerous studies involving several cohorts with a total of more than 900 pediatric patients on CSII $[6,7,10$ $12,15,21-23,27-41]$ reported a significant improvement in metabolic control, with a decrease of $0.5-1 \%$ in $\mathrm{HbA}_{1 \mathrm{c}}$. However, when CSII was compared to MDI in randomized crossover trials in children [42] or adolescents [43] and in randomized controlled trials of short duration in diabetic toddlers and young children $[5,13]$, there was no significant difference in $\mathrm{HbA}_{1 \mathrm{c}}$ values. One randomized controlled trial [24] reported a significantly lower $\mathrm{HbA}_{1 \mathrm{c}}$ in pediatric patients receiving CSII when compared to that of patients receiving MDI with glargine. However, in yet another study in pediatric patients, in which CSII was compared with MDI with glargine [44], there were no significant differences in metabolic control or incidence of hypoglycemia or ketoacidosis.

\section{Hypoglycemia}

Hypoglycemia is a serious risk associated with intensive therapy. Recurrent episodes of hypoglycemia at a young age have been associated with neurocognitive dysfunction. The fear of hypoglycemia prevalent in adolescents and families of children with T1DM may pose a barrier to improved glycemic control $[45,46]$. Several ob-

Insulin Pump Therapy in the Pediatric Age Group servational pediatric trials $[6,15,28,41]$ found a decrease in the rate of severe hypoglycemic episodes with CSII despite decreasing $\mathrm{HbA}_{1 \mathrm{c}}$ values, but none of the randomized controlled trials $[5,13,24,42,43]$ have shown a significant difference in the frequency of severe hypoglycemia.

Plasma glucose concentrations are often difficult to manage during prolonged periods of physical activity in patients with T1DM, and there is no way to suspend the action of long-acting insulin analogs once they have been injected subcutaneously. The Diabetes Research in Children Network (DirecNet) [47] demonstrated that the risk of hypoglycemia is sharply increased both during and on the night following a period of aerobic exercise of moderate intensity in pediatric patients maintained on a fixed basal insulin replacement regimen. However, the risk of hypoglycemia was markedly reduced in patients with an insulin pump by suspending the basal insulin infusion during exercise [48]. Another study [49] compared prolonged exercise in patients with CSII who either received half of the regular basal rate (temporary basal) during exercise or underwent temporary interruption of insulin delivery; the rate of hypoglycemia during exercise was similar in both groups, but a trend towards an increased rate of late hypoglycemia was observed in the temporary basal group [49].

Overall it would appear that CSII allows for greater flexibility in physical activity and may safely decrease the risk of hypoglycemia, particularly when the pump is suspended during prolonged activity.

\section{Quality of Life}

The improvement in lifestyle may be the most important reason for choosing CSII by the patient or parents. Evidence indicates that with CSII quality of life (QOL) and patient satisfaction are at least equal to or greater than with MDI $[5,21,50,51]$. Parents of infants and children reported that switching from injections to CSII granted them greater freedom and flexibility in their lives $[52,53]$. Adolescents also expressed a high level of satisfaction with pump therapy, noting that the increased flexibility in diet and the daily schedule gave a greater sense of control and independence, with fewer physical complaints [37].

\section{Disadvantages of CSII}

As CSII has grown in popularity, patients and physicians have begun to recognize some of its limitations. 
Table 1. Randomized and observational trials comparing MDI with CSII

\begin{tabular}{|c|c|c|c|c|c|c|c|c|}
\hline $\begin{array}{l}\text { Authors } \\
\text { (year of publication) }\end{array}$ & $\begin{array}{l}\text { Number } \\
\text { of } \\
\text { patients }\end{array}$ & $\begin{array}{l}\text { Mean age } \\
\text { (range) } \\
\text { years }\end{array}$ & $\begin{array}{l}\text { Mean } \\
\mathrm{HbA}_{1 \mathrm{c}} \\
\text { with } \\
\text { MDI, \% }\end{array}$ & $\begin{array}{l}\text { Mean } \\
\mathrm{HbA}_{1 \mathrm{c}} \\
\text { with } \\
\text { CSII, \% }\end{array}$ & $\begin{array}{l}\text { Mean } \\
\text { duration } \\
\text { of CSII } \\
\text { months }\end{array}$ & $\begin{array}{l}\text { Number of severe } \\
\text { hypoglycemic } \\
\text { episodes with MDI }\end{array}$ & $\begin{array}{l}\text { Number of severe } \\
\text { hypoglycemic } \\
\text { episodes with CSII }\end{array}$ & $\begin{array}{l}\text { Number } \\
\text { of DKA } \\
\text { episodes } \\
\text { with CSII }\end{array}$ \\
\hline \multicolumn{9}{|l|}{ Randomized trials } \\
\hline Fox et al. (2005) [5] & 26 & $3.8(1-6)$ & 7.46 & 7.24 & 6 & 1 & 0 & 1 \\
\hline Wilson et al. (2005) [13] & 19 & $3.6(1.7-6.1)$ & 8.04 & 7.8 & 12 & 1 & 1 & 0 \\
\hline Doyle et al. (2004) [24] & 32 & $12.5(8-21)$ & 8.1 & 7.2 & 4 & 4 & 0 & 1 \\
\hline Weintrob et al. (2003) [42] & 23 & $11.8(9.4-13.9)$ & 8.1 & 8 & 3.5 & 3 & 1 & 0 \\
\hline Cohen et al. (2003) [43] & 16 & $14.2(14.5-17.9)$ & 8.57 & 8.15 & 6 & 4 & 1 & 1 \\
\hline \multicolumn{9}{|l|}{ Observational trials } \\
\hline Weinzimer et al. (2004) [10] & 65 & $4.5(1.4-6.9)$ & 7.4 & 7.1 & 12 & $78 / 100$ patient years & $37 / 100$ patient years & 4 \\
\hline Shehadeh et al. (2004) [12] & 15 & $3.8(1-6)$ & 8.82 & 8.18 & 12 & $0.36 /$ patient year & $0.29 /$ patient year & 0 \\
\hline Plotnick et al. (2003) [28] & 95 & $12(4-18)$ & 8.1 & 7.7 & 12 & not available & not available & 1 \\
\hline Nimri et al. (2006) [41] & 279 & $17.7(1.6-40)$ & 8.5 & 7.8 & 29 & $94.6 / 100$ patient years & $34.4 / 100$ patient years & \\
\hline
\end{tabular}

\section{Risk of Hypoglycemia}

Pump therapy has the potential for hypoglycemia resulting from inappropriate insulin administration, whether intentional or unintentional [54]. With the current generation of pumps, a pump memory provides information on the insulin administered and a safety lockout feature acts to prevent hypoglycemia.

\section{Risk of DKA}

The lack of a subcutaneous depot of intermediate- or long-acting insulin and the short half-life of serum insulin during CSII increase patient susceptibility to ketonemia and DKA secondary to dislodgment or occlusion of the infusion set or pump failure [54]. Interruption of insulin may be intentional, to allow patients to participate in certain activities, or unintentional, caused by catheter occlusion, battery failure or depleted insulin supply. As with injection therapy, however, DKA can be prevented by adhering to published DKA prevention guidelines [55]. Since the alarm devices now available do not warn against leakage or dislodgment, it is recommended [3] that blood glucose should be monitored frequently and consistently with parental supervision; when the levels are elevated and/or when feeling ill, urine or serum ketones should also be tested to permit rapid appropriate intervention to avoid DKA.

\section{Infusion Site Reactions}

A few studies have recorded the incidence of skin irritation, lipohypertrophy, scarring and infusion site infections in children. The efforts to minimize these risks should include the strict adherence to proper infusion site preparation, insertion and rotation.

\section{Weight Gain}

Concerns have been raised that the improved glycemic control and greater flexibility in eating achieved with CSII might contribute to a greater weight gain than with other therapies. This, however, has not been borne out by a number of pediatric studies, which found no excess weight gain with CSII $[30,42,54]$.

\section{Psychosocial Stress}

The adoption of more intensive diabetes management coupled with the constant reliance on a medical appliance can weigh heavily on the patient and the family. The metabolic and psychosocial impacts of CSII therapy were examined in a meta-analysis that included five pediatric studies [56]. This did not reveal any consistent differences in anxiety, depression, QOL, self-esteem or family functioning [56].

\section{Cost of CSII}

In most countries the cost of a pump and related supplies is higher than the cost of MDI therapy. The additional costs for personnel involved in the initial education and training of patients and their caregivers as well as subsequent support of pump users should also be taken into account.

In summary, on the strength of these reports and studies, the verdict has generally been in favor of the use of insulin pump therapy in children and adolescents, its 
definite advantages being considered to outweigh considerably its possible disadvantages. Table 1 summarizes the randomized and observational trials comparing CSII with MDI.

\section{Conclusions}

In most pediatric centers a major gap between the target of a near-normal $\mathrm{HbA}_{1 c}$, as set by the DCCT $[1,9,40]$, and its actual achievement remains, as evidenced by comprehensive documentation [57]. To press towards this goal every effective therapy should be made available to as many pediatric patients as possible. Accumulating evidence suggests that CSII is not only a feasible, safe and well-accepted mode of therapy for pediatric T1DM patients, but has proven to provide improved glycemic control and QOL, as compared with MDI, without any notably greater risk. Minimizing the risks of CSII entails the same interventions that promote safety in all T1DM patients: proper education, frequent blood glucose monitor- ing, attention to diet and exercise and the maintenance of communication with the diabetes team [3]. The 'recipe' for successful pump treatment must be tailored to each individual patient and in all cases must have the continuing support of the experienced multidisciplinary diabetes team. The recent introduction of a real-time continuous glucose monitoring system providing readings $24 \mathrm{~h}$ a day constitutes a tool that will allow clinicians to far better utilize the variable basal rate capability of current insulin pumps. Similarly, analysis of postprandial glycemic excursions can provide a more rational method of dividing daytime insulin replacement between basal and bolus doses in CSII-treated patients. Preliminary results using real-time continuous glucose monitoring in youths with T1DM have been very promising [58].

Granted that no treatment of T1DM will ever be perfect until there is feedback control of insulin delivery (i.e., a closed loop), the recent approval of a sensor-augmented insulin pump (open-loop technology) suggests that we may finally be at the threshold of the development of a practically applicable artificial pancreas.

\section{References}

1 The Diabetes Control and Complications Trial Research Group: The effect of intensive treatment of diabetes on the development and progression of long-term complications in insulin-dependent diabetes mellitus. $\mathrm{N}$ Engl J Med 1993;329:977-986.

-2 Davies AG, Baun JD: A decade of insulin infusion pumps. Arch Dis Child 1988;63:329332.

-3 Phillip M, Battelino T, Rodriguez H, Danne T, Kaufman F: Use of insulin pump therapy in the pediatric age-group. Consensus statement. Diabetes Care 2007;30:1653-1662.

-4 Pozzilli P, Crino A, Schiaffini R, Manfrini S, Fioriti E, Coppolino G, Pitocco D, Visalli N, Corbi S, Spera S, Suraci C, Cervoni M, Matteoli MC, Patera IP, Ghirlanda G; The IMDIAB Group: A 2-year pilot trial of continuous subcutaneous insulin infusion versus intensive insulin therapy in patients with newly diagnosed type 1 diabetes (IMDIAB 8). Diabetes Technol Ther 2003;5:965-974.

5 Fox LA, Buckloh LM, Smith SD, Wysocki T, Mauras N: A randomized controlled trial of insulin pump therapy in young children with type 1 diabetes. Diabetes Care 2005;28: $1277-1281$.

Insulin Pump Therapy in the Pediatric Age Group
6 Boland EA, Grey M, Oesterle A, Fredrickson L, Tamborlane WV: Continuous subcutaneous insulin infusion. A new way to lower risk of severe hypoglycemia, improve metabolic control, and enhance coping in adolescents with type 1 diabetes. Diabetes Care 1999;22: 1779-1784.

7 Maniatis AK, Klingensmith GJ, Slover RH, Mowry CJ, Chase HP: Continuous subcutaneous insulin infusion therapy for children and adolescents: an option for routine diabetes care. Pediatrics 2001;107:351-356.

8 Weintrob $\mathrm{N}$, Schechter A, Benzaquen $\mathrm{H}$, Shalitin S, Lilos P, Galatzer A, Phillip M: Glycemic patterns detected by continuous subcutaneous glucose sensing in children and adolescents with type 1 diabetes mellitus treated by multiple daily injections vs continuous subcutaneous insulin infusion. Arch Pediatr Adolesc Med 2004;158:677-684.

-9 Beneficial effects of intensive therapy of diabetes during adolescence: outcomes after the conclusion of the Diabetes Control and Complications Trial (DCCT). J Pediatr 2001; 139:804-812.

10 Weinzimer SA, Ahern JH, Doyle EA, Vincent MR, Dziura J, Steffen AT, Tamborlane WV: Persistence of benefits of continuous subcutaneous insulin infusion in very young children with type 1 diabetes: a follow-up report. Pediatrics 2004;114:1601-1605.
11 Litton J, Rice A, Friedman N, Oden J, Lee MM, Freemark M: Insulin pump therapy in toddlers and preschool children with type 1 diabetes mellitus. J Pediatr 2002;141:490495.

12 Shehadeh N, Battelino T, Galatzer A, Naveh T, Hadash A, de Vries L, Phillip M: Insulin pump therapy for 1-6 year old children with type 1 diabetes. Isr Med Assoc J 2004;6:284286.

13 Wilson DM, Buckingham BA, Kunselman EL, Sullivan MM, Paguntalan HU, Gitelman SE: A two-center randomized controlled feasibility trial of insulin pump therapy in young children with diabetes. Diabetes Care 2005;28:15-19.

14 Colquitt J, Royle P, Waugh N: Are analogue insulins better than soluble in continuous subcutaneous insulin infusion? Results of a meta-analysis. Diabet Med 2003;20:863866.

15 Ahern JA, Boland EA, Doane R, Ahern JJ, Rose P, Vincent M, Tamborlane WV: Insulin pump therapy in pediatrics: a therapeutic alternative to safely lower HbAlc levels across all age groups. Pediatr Diabetes 2002;3:1015.

16 Hanas R: Selection for and initiation of continuous subcutaneous insulin infusion. Proceedings from a workshop. Horm Res 2002; 57(suppl 1):101-104.

Age Group

Horm Res 2008;70:14-21 
-17 Danne T, Battelino T, Kordonouri O, Hanas R, Klinkert C, Ludvigsson J, Barrio R, Aebi C, Gschwend S, Mullis PE, Schumacher U, Zumsteg U, Morandi A, Rabbone I, Cherubini V, Toni S, de Beaufort C, Hindmarsh $\mathrm{P}$, Sumner A, van Waarde WM, van den Berg N, Phillip M: A cross-sectional international survey of continuous subcutaneous insulin infusion in 377 children and adolescents with type 1 diabetes mellitus from 10 countries. Pediatr Diabetes 2005;6:193-198.

18 Danne T, Battelino T, Jarosz-Chobot P, Kordonouri O, Pankowska E, Phillip M; The PedPump Study Group: The PedPump Study: a low percentage of basal insulin and more than five daily boluses are associated with better centralized HbA1c in 1041 children on CSII from 17 countries (abstract). Diabetes 2005;54(suppl 1):A453.

-19 Rutledge KS, Chase HP, Klingensmith GJ, Walravens PA, Slover RH, Garg SK: Effectiveness of postprandial Humalog in toddlers with diabetes. Pediatrics1997;100:968972.

>20 Burdick J, Chase HP, Slover RH, Knievel K, Scrimgeour L, Maniatis AK, Klingensmith GJ: Missed insulin meal boluses and elevated hemoglobin Alc levels in children receiving insulin pump therapy. Pediatrics 2004;113: e221-e224.

-21 Tamborlane WV, Fredrickson LP, Ahern JH: Insulin pump therapy in childhood diabetes mellitus: guidelines for use. Treat Endocrinol 2003;2:11-21.

-22 Deiss D, Hartmann R, Hoeffe J, Kordonouri $\mathrm{O}$ : Assessment of glycemic control by continuous glucose monitoring system in 50 children with type 1 diabetes starting on insulin pump therapy. Pediatr Diabetes 2004; 5:117-121.

-23 Saha ME, Huuppone T, Mikael K, Juuti M, Komulainen J: Continuous subcutaneous insulin infusion in the treatment of children and adolescents with type 1 diabetes mellitus. J Pediatr Endocrinol Metab 2002;15: 1005-1010.

-24 Doyle EA, Weinzimer SA, Steffen AT, Ahern JA, Vincent M, Tamborlane WV: A randomized, prospective trial comparing the efficacy of continuous subcutaneous insulin infusion with multiple daily injections using insulin glargine. Diabetes Care 2004;27: 1554-1558.

-25 Heptulla RA, Allen HF, Gross TM, Reiter EO: Continuous glucose monitoring in children with type 1 diabetes: before and after insulin pump therapy. Pediatr Diabetes 2004;5:10-15

-26 Lepore G, Dodesini AR, Nosari I, Trevisan $\mathrm{R}$ : Effect of continuous subcutaneous insulin infusion vs. multiple daily insulin injection with glargine as basal insulin: an open parallel long-term study. Diabetes Nutr Metab 2004; 17:84-89.
27 Berhe T, Postellon D, Wilson B, Stone R: Feasibility and safety of insulin pump therapy in children aged 2 to 7 years with type 1 diabetes: a retrospective study. Pediatrics 2006; 117:2132-2137.

28 Plotnick LP, Clark LM, Brancati FL, Erlinger T: Safety and effectiveness of insulin pump therapy in children and adolescents with type 1 diabetes. Diabetes Care 2003;26:11421146.

29 Sulli N, Shashaj B: Continuous subcutaneous insulin infusion in children and adolescents with diabetes mellitus: decreased HbAlc with low risk of hypoglycemia. J Pediatr Endocrinol Metab 2003;16:393-399.

30 Willi SM, Planton J, Egede L, Schwarz S: Benefits of continuous subcutaneous insulin infusion in children with type 1 diabetes. J Pediatr 2003;143:796-801.

31 Liberatore R Jr, Perlman K, Buccino J, Artiles-Sisk A, Daneman D: Continuous subcutaneous insulin infusion pump treatment in children with type 1 diabetes mellitus. J Pediatr Endocrinol Metab 2004;17:223-226.

32 Mack-Fogg JE, Orlowski CC, Jospe N: Continuous subcutaneous insulin infusion in toddlers and children with type 1 diabetes mellitus is safe and effective. Pediatr Diabetes $2005 ; 6: 17-21$.

33 Tubiana-Rufi N, de Lonlay P, Bloch J, Czernichow P: Remission of severe hypoglycemic incidents in young diabetic children treated with subcutaneous infusion. Arch Pediatr 1996;3:969-976.

34 Battelino T, Ursic-Bratina N, Bratanic N, Zerjav-Tansek M, Avbelj M, Krzisnik C: The use of continuous subcutaneous insulin infusion (CSII) as the treatment of choice in children and adolescents with type 1 diabetes. Pediatr Endocrinol Rev 2004;1(suppl 3): 537-539.

35 Schiaffini R, Ciampalini P, Spera S, Cappa M, Crino A: An observational study comparing continuous subcutaneous insulin infusion (CSII) and insulin glargine in children with type 1 diabetes. Diabetes Metab Res Rev 2005;21:347-352.

36 Low KG, Massa L, Lehman D, Olshan JS: Insulin pump use in young adolescents with type 1 diabetes: a descriptive study. Pediatr Diabetes 2005;6:22-31.

37 Grylli V, Wagner G, Hafferl-Gattermayer A Schober E, Karwautz A: Disturbed eating attitudes, coping styles, and subjective quality of life in adolescents with type 1 diabetes. J Psychosom Res 2005;59:65-72.

-38 Glaser NS, Iden SB, Green-Burgeson D, Bennett C, Hood-Johnson K, Styne DM, Goodlin-Jones B: Benefits of an insulin dosage calculation device for adolescents with type 1 diabetes mellitus. J Pediatr Endocrinol Metab 2004;17:1641-1651.
39 Moreland EC, Tovar A, Zuehlke JB, Butler DA, Milaszewski K, Laffel LM: The impact of physiological, therapeutic and psychosocial variables on glycaemic control in youth with type 1 diabetes mellitus. J Pediatr Endocrinol Metab 2004;17:1533-1544.

40 Diabetes Control and Complications Trial Research Group: Effect of intensive diabetes treatment on the development and progression of long-term complications in adolescents with insulin-dependent diabetes mellitus: Diabetes Control and Complications Trial. J Pediatr 1994;125:177-188.

41 Nimri R, Weintrob N, Benzaquen H, Ofan R, Fayman G, Phillip M: Insulin pump therapy in youth with type 1 diabetes mellitus: a retrospective paired study. Pediatrics 2006;117: 2126-2131.

-42 Weintrob N, Benzaquen H, Galatzer A, Shalitin S, Lazar L, Fayman G, Lilos P, Dickerman Z, Phillip M: Comparison of continuous subcutaneous insulin infusion and multiple daily injection regimens in children with type 1 diabetes: a randomized open crossover trial. Pediatrics 2003;112:559564

43 Cohen D, Weintrob N, Benzaquen $\mathrm{H}$, Galatzer A, Fayman G, Phillip M: Continuous subcutaneous insulin infusion versus multiple daily injections in adolescents with type I diabetes mellitus: a randomized open crossover trial. J Pediatr Endocrinol Metab 2003; 16:1047-1050.

-44 Garcia-Garcia E, Galera R, Aguilera P, Cara $\mathrm{G}$, Bonillo A: Long-term use of continuous subcutaneous insulin infusion compared with multiple daily injections of glargine in pediatric patients. J Pediatr Endocrinol Metab 2007;20:37-40.

45 Jeha GS, Karaviti LP, Anderson B, Smith EO, Donaldson S, McGirk TS, Haymond MW: Insulin pump therapy in preschool children with type 1 diabetes mellitus improves glycemic control and decreases glucose excursions and the risk of hypoglycemia. Diabetes Technol Ther 2005;7:876-884.

$\checkmark 46$ Marrero DG, Guare JC, Vandagriff JL, Fineberg NS: Fear of hypoglycemia in the parents of children and adolescents with diabetes: maladaptive or healthy response? Diabetes Educ 1997;23:281-286.

47 The Diabetes Research in Children Network (DirecNet) Study Group: The effects of aerobic exercise on glucose and counterregulatory hormone concentrations in children with type 1 diabetes. Diabetes Care 2006;29: 20-25.

48 Tansey M, Tsalikian E, Beck RW, FialloScharer R, Janz K, Fox L, Wilson D, Weinzimer S, Tamborlane W, Steffes M, Xing D, Ruedy K; Diabetes Research in Children Network (DirecNet) Study Group: Stopping basal insulin during exercise markedly reduces the risk of hypoglycemia in children with type 1 diabetes on insulin pump therapy (abstract). Diabetes 2006;55(suppl 1): A240. 
49 Admon G, Weinstein Y, Falk B, Weintrob N, Benzaquen H, Ofan R, Fayman G, Zigel L, Constantini N, Phillip M: Exercise with and without an insulin pump among children and adolescents with type 1 diabetes mellitus. Pediatrics 2005; 116:e348-e355.

50 McMahon SK, Airey FL, Marangou DA, McElwee KJ, Carne CL, Clarey Davis EA, Jones TW: Insulin pump therapy in children and adolescents: improvements in key parameters of diabetes management including quality of life. Diabet Med 2005;22:92-96.

51 Weintrob N, Shalitin S, Phillip M: Why pumps? Continuous subcutaneous insulin infusion for children and adolescents with type 1 diabetes. Isr Med Assoc J 2004;6:271275.

-52 Sullivan-Bolyai S, Knafl K, Tamborlane W, Grey M: Parents' reflections on managing their children's diabetes with insulin pumps. J Nurs Scholarsh 2004;36:316-323.
53 Maniatis AK, Toig SR, Klingensmith GJ, Fay-Itzkowitz E, Chase HP: Life with continuous subcutaneous insulin infusion (CSII) therapy: child and parental perspectives and predictors of metabolic control. Pediatr Diabetes 2001;2:51-57.

54 Hanas R, Adolfsson P: Insulin pumps in pediatric routine care improve long-term metabolic control without increasing the risk of hypoglycemia. Pediatr Diabetes 2006;7:2531.

55 Wolfsdorf J, Glaser N, Sperling MA; American Diabetes Association: Diabetic ketoacidosis in infants, children, and adolescents: a consensus statement from the American Diabetes Association. Diabetes Care 2006;29. 1150-1159.
56 Weissberg-Benchell J, Antisdel-Lomaglio J, Seshadri R: Insulin pump therapy: a metaanalysis. Diabetes Care 2003;26:1079-1087.

57 Mortensen HB, Robertson KJ, Aanstoot HJ, Danne T, Holl RW, Hougaard P, Atchison JA, Chiarelli F, Daneman D, Dinesen B, Dorchy H, Garandeau P, Greene S, Hoey H, Kaprio EA, Kocova M, Martul P, Matsuura N, Schoenle EJ, Sovik O, Swift PG, Tsou RM, Vanelli M, Aman J: Insulin management and metabolic control of type 1 diabetes mellitus in childhood and adolescence in 18 countries. Hvidore Study Group on Childhood Diabetes. Diabet Med 1998;15:752-759.

58 Deiss D, Bolinder J, Riveline JP, Battelino T, Bosi E, Tubiana-Rufi N, Kerr D, Phillip M: Improved glycemic control in poorly controlled patients with type 1 diabetes using real-time continuous glucose monitoring. Diabetes Care 2006;29:2730-2732. 